\section{Prevalence of Metabolic Syndrome in Okayama Prefecture, Japan}

Nobuyuki Miyatake, Yuriko Kawasaki, Hidetaka Nishikawa, Sumiko Takenami and Takeyuki Numata

Key words: metabolic syndrome, prevalence, waist circumference, Japanese

\section{(DOI: 10.2169/internalmedicine.45.1509)}

Metabolic syndrome, since the work of Reaven (1), refers to the state in which metabolic risk factors for cardiovascular diseases are clustered in individuals and it increases the risk of morbidity and mortality of cardiovascular disease. Studies have shown that metabolic factors tend to aggregate in individuals, and that clustering is more harmful than having a single individual factor (2). The criterion of metabolic syndrome has been defined recently in Japan (3). The syndrome was defined, among men with a waist circumference in excess of $85 \mathrm{~cm}$ and women with a waist circumference in excess of $90 \mathrm{~cm}$, as having 2 or more components from the following: 1) triglycerides $\geqq 150 \mathrm{mg} / \mathrm{dl}$ and/or $\mathrm{HDL}$ cholesterol $<40 \mathrm{mg} / \mathrm{dl}, 2$ ) blood pressure $\geqq 130 / 85 \mathrm{mmHg}$, 3) fasting plasma glucose $\geqq 110 \mathrm{mg} / \mathrm{dl}$. However, the prevalence of metabolic syndrome in Japan has not been fully investigated.

We used data of 12,712 Japanese (3,900 men and 8,812 women) aged 20-79 years (43.3 \pm 14.2$)$, who received annual health check-ups at Okayama Southern Institute of Health with informed consent. We measured anthropometric parameters i.e. body height, body weight, waist circumference and hip circumference. Waist circumference was measured at the umbilical level. Of the 12,712 Japanese, although 1,754 men $(45.0 \%)$ had a waist circumference in excess of $85 \mathrm{~cm}$, only 468 women $(5.3 \%)$ had a waist circumference exceeding $90 \mathrm{~cm}$ (Table 1).

To clarify the prevalence of metabolic syndrome in Okayama prefecture, Japan, we used data of 2,228 Japanese

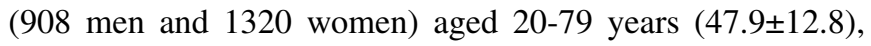
who undertook blood examination and blood pressure measurements (Table 1). Among the 2,228 Japanese subjects, 475 men $(52.3 \%)$ had a waist circumference in excess of $85 \mathrm{~cm}$ and 80 women $(6.1 \%)$ had a waist circumference exceeding $90 \mathrm{~cm}$. In addition, the prevalence of metabolic syndrome gradually increased with age under the age of 70 and 279 men $(30.7 \%)$ were diagnosed as having metabolic syndrome. In turn, the prevalence of metabolic syndrome gradually in-

Table 1. Number of Subject with Metabolic Syndrome and Sub Criteria in Okayama Prefecture Japan

\begin{tabular}{|c|c|c|c|c|c|c|}
\hline Age & Number of mibjects & $\begin{array}{l}\text { Waist oroumference } \\
\text { Waist } \geq 85 \mathrm{om}(\text { Men) } \\
\text { Waist } \geq 90 \mathrm{~cm} \text { (Women) }\end{array}$ & 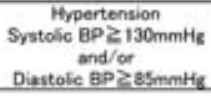 & $\begin{array}{l}\text { Impaired flucose tolerance } \\
\text { Fasting BS } \geq 110 \mathrm{mg} / \mathrm{dl}\end{array}$ & $\begin{array}{l}\text { Dysioidemis } \\
\text { Trighyceride } \geq 150 \mathrm{mg} / \mathrm{dl} \\
\text { and } / \text { or } \\
\text { HDL eholesterol }<40 \mathrm{mg} / \mathrm{d}\end{array}$ & Metabolic syndrome \\
\hline \multicolumn{7}{|c|}{12,712 Japanese } \\
\hline \multicolumn{7}{|c|}{ Men } \\
\hline $20-20$ & 769 & $176(22.3)$ & & & & \\
\hline $30-39$ & 906 & $377(41.6)$ & & & & \\
\hline $40-49$ & 812 & $418(515)$ & & & & \\
\hline $50-59$ & 718 & $412(57.4)$ & & & & \\
\hline $60-60$ & 522 & $288(552)$ & & & & \\
\hline $70-79$ & 153 & $83(542)$ & & & & \\
\hline Total & 3900 & $1754(450)$ & & & & \\
\hline \multicolumn{7}{|l|}{ Women } \\
\hline $20-20$ & 2060 & $38(1.9)$ & & & & \\
\hline $30-39$ & 1812 & $48(26)$ & & & & \\
\hline $40-49$ & 1770 & $96(5.4)$ & & & & \\
\hline $50-59$ & 1768 & $114(6.4)$ & & & & \\
\hline $60-69$ & 1145 & $123(107)$ & & & & \\
\hline $70-79$ & 237 & $49(20) 7)$ & & & & \\
\hline Total & 8812 & $468(5.3)$ & & & & \\
\hline \multicolumn{7}{|c|}{2.228 Japanese } \\
\hline Men & & & & & & \\
\hline $20-20$ & 82 & $24(29.3)$ & $28(34.1)$ & $6(7.3)$ & $23(28.0)$ & $10(12.2)$ \\
\hline $30-39$ & 180 & $87(48.3)$ & $87(483)$ & $24(13.3)$ & $89(49.4)$ & $40(22.2)$ \\
\hline $40-49$ & 268 & $162(60.4)$ & $167(62.3)$ & $62(23.1)$ & $150(56.0)$ & $97(36.2)$ \\
\hline $50-59$ & $m 2$ & $124(559)$ & $146(65.8)$ & $88(39.6)$ & $109(49.1)$ & $75(33.8)$ \\
\hline $60-69$ & 122 & $67(549)$ & $89(730)$ & $49(40.2)$ & $73(59.8)$ & $50(41,0)$ \\
\hline $70-79$ & 34 & $11(324)$ & $25(73.5)$ & $9(26.5)$ & $12(35.3)$ & $7(20.6)$ \\
\hline Total & 908 & $475(52.3)$ & $542(59.7)$ & 238 (26.2) & $456(50.2)$ & $279(30.7)$ \\
\hline \multicolumn{7}{|l|}{ Women } \\
\hline $20-20$ & 147 & $3(20)$ & $15(10.2)$ & $1(0,7)$ & $24(16.3)$ & $1(0.7)$ \\
\hline $30-39$ & 180 & $6(3.3)$ & $31(172)$ & $5(2.8)$ & $40(22.2)$ & $1(0.6)$ \\
\hline $40-49$ & 325 & $18(5.5)$ & $113(348)$ & $19(5.8)$ & $82(25.2)$ & $7(2.2)$ \\
\hline $50-59$ & 370 & $25(6.8)$ & $210(568)$ & $46(124)$ & $138(37.3)$ & $19(5.1)$ \\
\hline $60-69$ & 238 & $19(80)$ & $165(69.3)$ & $48(20.2)$ & $108(44.5)$ & $13(5.5)$ \\
\hline $70-79$ & 60 & $9(150)$ & $51(850)$ & $18(300)$ & $38(63.3)$ & $7(11,7)$ \\
\hline Total & 1320 & $80(6.1)$ & $585(443)$ & $137(104)$ & $428(324)$ & $48(3.6)$ \\
\hline
\end{tabular}

Okayama Southern Institute of Health, Okayama

Received for publication July 21, 2005; Accepted for publication October 10, 2005

Reprint requests should be addressed to Nobuyuki Miyatake, Okayama Southern Institute of Health, 408-1 Hirata, Okayama 700-0952 
creased with age, especially over the age of 50, and only 48 women $(3.6 \%)$ were diagnosed with metabolic syndrome. We also investigated the prevalence of metabolic syndrome using the definition of International Diabetes Federation (IDF) (4) and Adult Treatment Panel III (ATPIII) (5); 339 men $(37.3 \%)$ and 58 women $(4.4 \%)$ were diagnosed with metabolic syndrome by IDF and 244 men (26.9\%) and 194 women $(14.7 \%)$ were diagnosed with metabolic syndrome by ATPIII.

The main finding of this study was that we revealed the prevalence of metabolic syndrome in both sexes in Japan. In addition, sex difference in the prevalence of metabolic syndrome was noted from our study. This was due to the fact that the prevalence of women with a waist circumference in excess of $90 \mathrm{~cm}$ was significantly lower than that of men with a waist circumference exceeding $85 \mathrm{~cm}$. We could not explore whether metabolic syndrome is closely linked to future cardiovascular disease or the importance of sex differences. Follow-up studies are required to prove such links. In conclusion, the prevalence of the metabolic syndrome was $30.7 \%$ in men and $3.6 \%$ in women in Okayama Prefecture, Japan.

\section{References}

1. Reaven GM. Banting lecture 1988. Role of insulin resistance in human disease. Diabetes 37: 1595-1607, 1988.

2. Wilson PW, Kannel WB, Silbershatz H, D'Agostino RB. Clustering of metabolic factors and coronary heart disease. Arch Intern Med 159: 1104-1109, 1999.

3. An examination committee for criterion of metabolic syndrome: Definition and criteria of metabolic syndrome. Nippon Naika Gakkai Zasshi 94: 794-809, 2005 (Japanese).

4. International Diabetes Federation: The IDF consensus worldwide definition of the metabolic syndrome. $1^{\text {st }}$ International Congress on Prediabetes and the Metabolic Syndrome in Berlin, Germany in April 2005.

5. Expert panel on detection, evaluation, and treatment of high blood cholesterol in adults. Executive Summary of the Third Report of The National Cholesterol Education Program (NCEP) Expert Panel on Detection, Evaluation and Treatment of High Blood Cholesterol in Adults (Adult Treatment Panel III). JAMA 285: 2486-2497, 2001.

(C) 2006 The Japanese Society of Internal Medicine http://www.naika.or.jp/imindex.html 